\title{
Family-supportive organization perceptions, multiple dimensions of work-family conflict, and employee satisfaction: A test of model across five samples is
}

\author{
Laurent M. Lapierre $^{\mathrm{a}, *}$, Paul E. Spector ${ }^{\mathrm{b}}$, Tammy D. Allen ${ }^{\mathrm{b}}$, Steven Poelmans ${ }^{\mathrm{c}}$, \\ Cary L. Cooper ${ }^{\mathrm{d}}$, Michael P. O’Driscoll ${ }^{\mathrm{e}}$, Juan I. Sanchez ${ }^{\mathrm{f}}$, Paula Brough ${ }^{\mathrm{g}}$, \\ Ulla Kinnunen ${ }^{\mathrm{h}}$ \\ ${ }^{a}$ Telfer School of Management, University of Ottawa, 55 Laurier Street East, Ottawa, Ont., K1N 6N5 Canada \\ ${ }^{\mathrm{b}}$ Department of Psychology, University of South Florida, 4202 East Fowler Ave, PCD4118G, Tampa, FL 33620, USA \\ ${ }^{\mathrm{c}}$ IESE Business School, University of Navarra, 21 Avenida Pearson, 08034, Barcelona, Spain \\ d Management School, Lancaster University, Bailrigg, Lancaster, LA1 4YX, UK \\ ${ }^{\mathrm{e}}$ Department of Psychology, University of Waikato, Gate 1 Knighton Road, Private Bag 3105 Hamilton 3240, New Zealand \\ ${ }^{\mathrm{f}}$ Department of Management/International Business, University Park, Florida International University, Miami, FL 33199-0001, USA \\ ${ }^{\mathrm{g}}$ School of Psychology, Mt Gravatt Campus, Griffith University, 170 Kessels Road, NATHAN QLD 4111, Queensland, Australia \\ ${ }^{\mathrm{h}}$ University of Jyväskylä, Family Research Unit, P.O. Box 35, FIN-40351 Jyväskylä, Finland
}

Received 21 September 2007

Available online 16 February 2008

\begin{abstract}
Using samples of managers drawn from five Western countries, we tested a theoretical model linking employees' perceptions of their work environment's family-supportiveness to six different dimensions of work-family conflict (WFC), and to their job satisfaction, family satisfaction, and life satisfaction. Our results are consistent with a causal process whereby employees working in an environment viewed as more family-supportive experience lower levels of WFC. Reduced WFC then translates into greater job and family satisfaction, followed by greater overall life satisfaction. These findings were generalizable across the five samples.
\end{abstract}

(C) 2008 Elsevier Inc. All rights reserved.

Keywords: Work-family conflict; Organizational support; Job satisfaction; Family satisfaction; Life satisfaction

\section{Introduction}

Work-family conflict (WFC) is recognized as a major issue affecting both individual employees and their employers. Preliminary research shows that the more employees perceive their work environment as

\footnotetext{
This research was supported in part by Grant 410-2006-0209 from the Social Sciences and Humanities Research Council of Canada.

* Corresponding author. Fax: +1 6135625164.

E-mail address: lapierre@telfer.uottawa.ca (L.M. Lapierre).
} 
family-supportive, the less they experience WFC (Allen, 2001). Moreover, there are theoretical and empirical reasons to expect that by reducing WFC, a family-supportive work environment would enhance employees' satisfaction with their job, family, and life in general. In addition, despite the impressive body of research that has been devoted to WFC, there have been few studies that have assessed WFC as a multidimensional construct, other than those that distinguish between directions of conflict, namely work interference with family (WIF) versus family interference with work (FIW). Based primarily on Greenhaus and Beutell's (1985) seminal theoretical work, Carlson, Kacmar, and Williams (2000) developed a six-dimensional measure of WFC designed to capture three forms of WFC (time-based, strain-based, and behavior-based) in each direction (WIF and FIW). Eby, Casper, Lockwood, Bordeaux, and Brinley (2005) noted that more research on this multidimensional conceptualization of WFC would be valuable in providing a finer-grained understanding of this phenomenon.

In the present study we investigated relationships between family-supportive organization perceptions (FSOP, i.e., the extent employees view their work environment as being family-supportive), the six WFC dimensions, and satisfaction with the job, family, and life. Fig. 1 provides a graphic depiction of our proposed theoretical model integrating the relationships among these variables. To increase the model's generalizability, we collected data from samples of managers in five countries, and conducted tests of invariance for both the measurement model and the theoretical structural model.

\subsection{Family-supportive work environments}

There has been a growing recognition by scholars that making family-friendly benefits (e.g., flextime, parttime work, onsite daycare) available to employees or providing them with family-supportive supervision is insufficient to significantly reduce their WFC (Allen, 2001; Friedman, 1990; Friedman \& Galinsky, 1992; Perlow, 1995; Thompson, Beauvais, \& Lyness, 1999). What is needed, according to these authors, is a family-supportive organizational culture or work environment — one that openly acknowledges employees' family and personal situations by promoting flexibility, tolerance, and support for family needs and obligations. The guiding philosophy in organizations offering such a work environment is that success is not contingent upon employees making work their top priority in life. Thus, in such environments, physical presence at work ("face time") and long hours spent at work would not be relied upon as the sole indicators of employees' organizational commitment and value to the firm (Friedman \& Galinsky, 1992; Perlow, 1995). This philosophy would

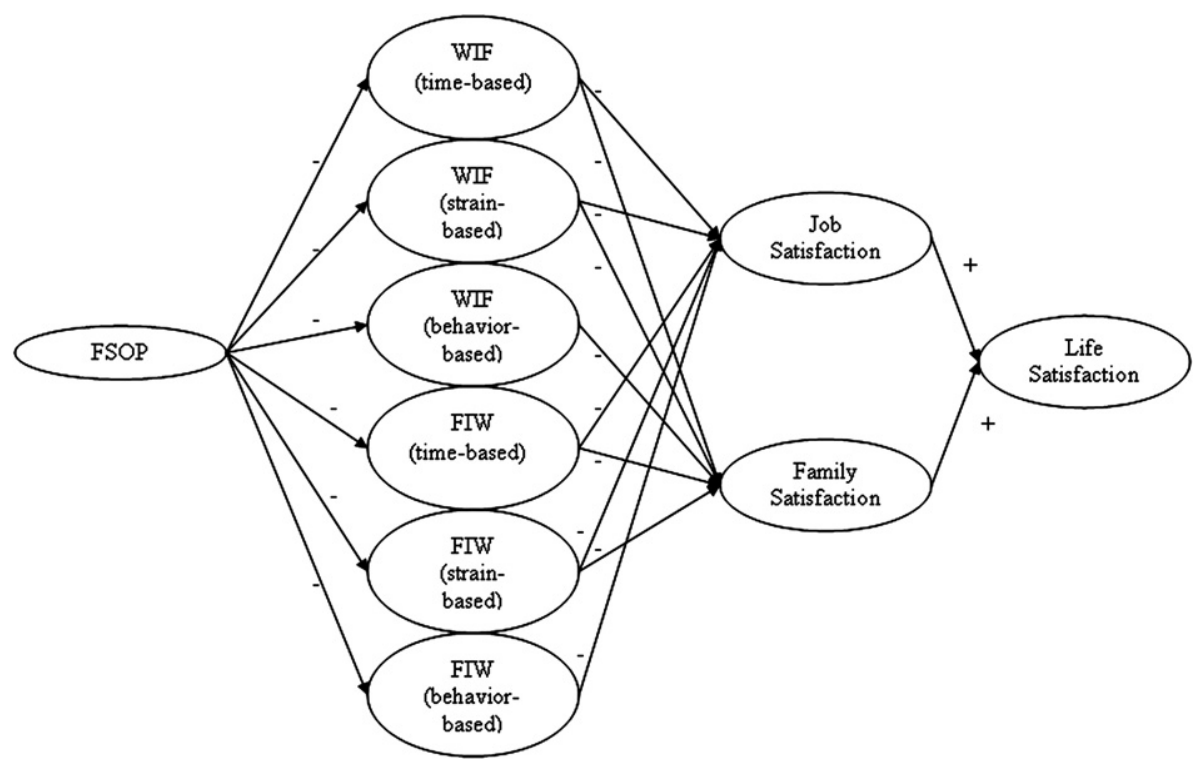

Fig. 1. Proposed theoretical model. 
theoretically help reduce the incompatibility between employees' work and family demands. For example, employees working in such an environment would feel more comfortable devoting time and energy to their family without fear of negative career repercussions, and would feel less pressured to prioritize work at the expense of family (Allen, 2001; Friedman \& Galinsky, 1992).

In an effort to operationalize the family-supportive work environment construct described above, Allen (2001) developed a measure labeled family-supportive organization perceptions (FSOP). Thompson et al. (1999) had previously developed a similar measure, although theirs combined managerial support (support provided by managers/supervisors) with global perceptions of the organization's work environment. In an effort to disentangle these two constructs, Allen designed her measure to distinctly capture employees' global perceptions of whether their organization's work environment is supportive of their family-related needs. Theoretically, these perceptions would fuel employees' attitudinal and behavioral responses more so than objective aspects of their work environment, such as the availability of family-friendly organizational benefits (James \& McIntyre, 1996). According to Allen's (2001) findings, employees working in an environment perceived as more family-friendly reported less WFC, even after controlling for the availability of family-friendly benefits and the receipt of family-supportive supervision. This supports the view that perceptions of the work environment play a unique role in explaining WFC. Furthermore, her results suggest that employees' familysupportive organization perceptions may be partially influenced by the family-supportive supervision they receive and the availability of family-friendly benefits. Finally, Allen found, as did Thompson et al. (1999), that FSOP correlated positively with employees' actual use of family-friendly benefits, particularly flexible work arrangements (e.g., flextime, compressed work weeks, telework). This reinforced the idea that work environments viewed as more family-supportive could reduce employees' fear that devoting time and energy to their family (by using benefits) could hurt their career. Hence, FSOP may be a key indicator of whether employees' work environment is instrumental in reducing WFC.

Allen's (2001) FSOP measure relates with WFC. Yet, little research attention has been given to its measurement properties and it has rarely been included in tests of theoretical models involving WFC. Including it in our study enabled an examination of the potential for employees' perceived work environment to reduce WFC and enhance their subjective well-being. In the following paragraphs, we explain the theoretical basis for the relationships in our proposed model.

\subsection{FSOP and multiple dimensions of WFC}

Allen's (2001) study involved an overall measure of WIF. With research suggesting that WFC can exist in six distinct dimensions (Carlson et al., 2000), one question spurred by Allen's (2001) findings is whether FSOP relates to all or only a subset of these WFC dimensions. We expect FSOP to negatively relate to all three forms as well as both directions of WFC. This represents a departure from much of the previous WFC research, which suggests that the work environment influences WIF but not FIW (for a review, see Frone, 2003). Below we explain why FSOP would relate to both directions of time-based and strain-based conflict, after which we elucidate the link between FSOP and both directions of behavior-based conflict.

\subsubsection{Relationships of FSOP with time-based and strain-based WIF}

Time-based WIF reflects work demands that deplete the time employees need for their family activities. FSOP should relate negatively to time-based WIF to the extent that working in a family-supportive environment prevents situations where work time demands interfere with employees' family activities. As noted above, family-supportive work environments enable employees to attend to family matters when needed because there is general support for employees' efforts to attend to such matters. When working in such en environment, employees would be more comfortable taking the time they need to address family-related issues or concerns.

Strain-based WIF indicates that work stressors create levels of strain that hamper employees' mood and energy even when they are home. Family-supportive work environments advocate that work need not be the primary priority in one's life - that work is not "everything" in life (Allen, 2001; Friedman \& Galinsky, 1992; Perlow, 1995). Previous research suggests that the organizational environment can shape an employee's attitudes and behaviors (Ostroff, Kinicki, \& Tamkins, 2003). Thus, when working in an environment perceived 
as more family-supportive, employees are not likely to feel as pressured to completely invest themselves in their work role. This should limit the extent that they get worried or concerned about work issues, thereby reducing the probability that work-induced strains interfere with their family activities. Thus, we would expect a negative relationship between FSOP and strain-based WIF.

\subsubsection{Relationships of FSOP with time-based and strain-based FIW}

Greenhaus and Beutell (1985) argued that simultaneous pressures from both the work and family domains are necessary for WFC to be experienced. If this is true, we would expect FSOP to relate negatively to timeand strain-based FIW. High FSOP suggests that there is more perceived tolerance for the time employees devote to family-related matters (Allen, 2001). This is consistent with the general assumption that family-supportive work environments give less importance to the amount of time one is physically present at work (Friedman \& Galinsky, 1992; Perlow, 1995). With less pressure to spend time at work, particularly when family time demands are great, employees are less likely to view time spent on family-related matters as interfering with their work role. Furthermore, the flexibility promoted by family-supportive work cultures should minimize the extent to which time spent dealing with family matters interferes with work performance. Thus, FSOP should relate negatively with time-based FIW.

Similarly, in a family-supportive work environment there is greater perceived tolerance for talking about nonwork problems and strains at work (Allen, 2001). Thus, the workplace provides social support that might help to buffer the impact of stressors on strains (Bliese \& Britt, 2001). As such, employees experiencing familyinduced strains in a family-supportive work environment should be less fearful of being stigmatized for having nonwork problems become known at work, and the support at work may well mitigate the impact of such problems on strain. Both would reduce strain-based FIW.

\subsubsection{FSOP and behavior-based WFC}

A negative relationship between FSOP and behavior-based forms of WFC is also theoretically plausible, although for a reason quite different than for the WFC dimensions discussed above. Behavior-based WIF indicates that behaviors expected at work cause problems if they are enacted with one's family, while behaviorbased FIW indicates that behaviors expected at home would cause problems if they are used at work. It is when work and family roles differ markedly in their behavioral expectations or norms that such conflict can arise. In some work environments, people may be expected to be competitive and aggressive. According to Greenhaus and Beutell (1985), behavioral expectations at work denoting such individualism and selfishness would be incompatible with behavioral expectations in the family domain, such as being supportive and tolerant of one another. However, if behavioral expectations at work are similar in nature to those on the family front, then behavior-based WIF and FIW would be less likely to occur.

Behavioral norms typifying a family-supportive work environment include being supportive of employees' family needs, and showing tolerance and acceptance when employees address family issues at work (Allen, 2001; Friedman \& Galinsky, 1992). It would be unreasonable to expect behavioral norms such as competitiveness and aggression to exist in a family-supportive work environment as they would contradict the notions of support and tolerance. If Greenhaus and Beutell (1985) are correct in implying that mutual support and tolerance are typically expected in most families (although not necessarily always displayed), then the behavioral norms typifying a family-supportive work environment would be similar in nature to the behavioral expectations of most families. Working in a family-supportive environment should therefore reduce the likelihood of behavioral incompatibilities between work and family. Thus, FSOP should relate negatively to behavior-based WIF and FIW.

\subsection{WFC dimensions and employee satisfaction}

In the following paragraphs, we explain the theoretical relationships between each of the six WFC dimensions and employees' satisfaction with their job, their family, and their life overall.

\subsubsection{Time-based and strain-based WFC and employees' job and family satisfaction}

WFC is often considered from a role stress perspective because it represents an incompatibility between the demands of two roles (Kahn, Wolfe, Quinn, Snoek, \& Rosenthal, 1964; Katz \& Kahn, 1978). Work 
role stressors typically induce negative mood, which leads to negative job attitudes (e.g., Beehr \& Glazer, 2005). As stressors originating in the work role, it is reasonable to expect time- and strain-based WIF to relate negatively to job satisfaction, despite some research suggesting job satisfaction would result from FIW and not WIF (e.g., Carlson \& Kacmar, 2000; Frone, Yardley, \& Markel, 1997; O’Driscoll, Ilgen, \& Hildreth, 1992). Employees experiencing these two forms of WIF would blame their organizations and thus be less satisfied with their jobs for having depleted the time and energy they need for participating in family activities. This is consistent with research reporting that WIF relates negatively to employee intentions to quit their job and to actual turnover (e.g., Greenhaus, Parasuraman, \& Collins, 2001; Kirchmeyer \& Cohen, 1999). We would also expect both forms of WIF to negatively relate to family satisfaction because the reduced time and energy that employees can devote to their families as a result of their work demands could erode the quality of their family experiences (Aryee, Fields, \& Luk, 1999; Frone, Russell, \& Cooper, 1992).

Analogous arguments can be made in the case of time- and strain-based FIW. These dimensions should negatively relate to job satisfaction because insufficient time and energy would be available to ensure satisfying work-related experiences. Indeed, a person experiencing a high level of time- and/or strain-based FIW may have more difficulty making a positive impression upon his/her immediate supervisor, thereby thwarting future work-related growth opportunities that most employees would find satisfying, such as having greater autonomy and being given more important assignments (Lapierre, Hackett, \& Taggar, 2006). Also, despite the suggestion based on extant research that family satisfaction results from WIF and not FIW (Frone, 2003), both forms of FIW should also relate negatively with family satisfaction if employees blame their family role for sapping the time and energy they need to fulfill their work commitments.

Although the preceding arguments may give little reason to distinguish between time-based and strainbased WFC, we would expect each form of conflict to explain unique variation in job and family satisfaction because one does not necessarily imply the presence of the other. For example, specific role demands may physically or emotionally drain people despite the fact that they spend few hours in that role.

\subsubsection{Behavior-based WFC and employees' job and family satisfaction}

As noted by Edwards and Rothbard (2000), behavior-based WFC does not reflect one role depleting resources needed for the other role (as is the case for time- and strain-based WFC), but rather an incompatibility between the behaviors expected in each role. While employees may blame and thus be less satisfied with one role for draining time and/or energy needed in the other role, it is unclear whether employees would blame their family for behavior-based FIW or their work for behavior-based WIF. Thus, we would not expect behavior-based FIW to relate negatively with family satisfaction, nor would we expect behavior-based WIF to negatively relate to job satisfaction.

However, because behavior-based WIF can potentially cause problems at home, this dimension of WFC should relate negatively to family satisfaction. Similarly, because behavior-based FIW may lead to problems at work, this particular dimension of WFC should be negatively linked to job satisfaction.

\subsubsection{WFC dimensions, role-specific satisfaction, and life satisfaction}

Life satisfaction has been regarded as one of the foremost indicators of one's overall quality of life (Moons, Budts, \& De Geest, 2006). With work and family likely being among the most important roles individuals hold in life, an inability to balance and meet the demands of these roles would likely be a significant source of life dissatisfaction. In support of this basic argument, Allen, Herst, Bruck, and Sutton (2000) reported an average corrected correlation of -.28 between WIF and life satisfaction.

Aryee et al. (1999) proposed and found that WIF and FIW each related negatively to life satisfaction through reduced levels of family and job satisfaction. This is consistent with the notion that an individual's life satisfaction is a function of satisfaction with various aspects of life (Rice, Frone, \& McFarlin, 1992). We would therefore expect that job satisfaction and family satisfaction would serve as mediators in the relationships between WFC dimensions and life satisfaction. That is, WFC dimensions will be negatively related with job and family satisfaction, which in turn would relate positively with life satisfaction. 


\subsection{Model summary}

Overall, our proposed theoretical model can be summarized as follows: perceptions that the organization's work environment is family-supportive help to reduce multiple dimensions of WFC. In turn, family and job satisfaction are enhanced, which subsequently increases life satisfaction. Empirical support for this model would suggest that employees' perception of their work environment can play an important role in helping them to avoid work-family interference as well as the psychological strains that may result.

\subsection{Generalizability of proposed model}

To determine whether our proposed theoretical model generalizes beyond a single sample, we used five independent samples. Providing evidence of model generalizability would reduce concerns that our results are largely reflective of sampling error. Rather than selecting samples from the same geographic region, we drew each from a different country to provide a more conservative test of model generalizability. An important consideration when conducting cross-national research of this nature is whether the countries involved are culturally similar or not. Significant cultural variation across samples may cause construct measurement problems, where individuals from culturally different samples interpret the meaning of items in different ways. Indeed, Liu, Borg, and Spector (2004) found that the measurement properties of a job satisfaction scale varied across culturally dissimilar samples, but not within culturally similar samples. Also, relationships between constructs may not be generalizable across samples from markedly different cultures. For example, Spector et al. (2007) and Spector et al. (2004) found that relationships between work demands and WFC were stronger in individualistic than in collectivistic cultures. Also, Spector et al. (2007) found that WFC was more strongly related to job satisfaction and turnover intentions in individualistic than in collectivistic cultures. These findings support the argument that work and family demands are more likely to be related to such inter-role conflict and to affective/behavioral reactions in individualistic cultures than in collectivistic ones.

In sum, to provide a conservative yet fair test of our model's generalizability - that is, one where measurement invariance and structural model invariance are theoretically expected across samples - it was important to select samples from countries that previous research indicates are culturally similar. We drew our samples from Canada, the United States, Australia, New Zealand, and Finland. Previous research suggests that these countries share a similarly high level of individualism (Hofstede, 1980; House, Hanges, Javidan, Dorfman, \& Gupta, 2004; Schwartz, 1994). We focused on this particular cultural dimension given previous cross-national research (e.g., Spector et al., 2004, 2007) highlighting the relevance of individualism-collectivism to WFC theories involving characteristics of the work environment and employee attitudes. Finland was included to test generalizability beyond English-speaking countries.

\section{Method}

\subsection{Participants}

Participant samples were drawn internationally as part of the second phase of the Collaborative International Study of Managerial Stress (CISMS 2). A central project team designed the study and questionnaire, recruited research partners to collect data in their countries, and compiled data across the different country datasets. Research partners strived to ensure that participants were managers and each worked for a separate organization with diverse industries represented. Procedures varied in individual countries for data collection (e.g., some used management associations to recruit participants, whereas others used business school alumni lists). In some countries, a variety of methods were used to enssure a heterogeneous sample of managers. For example, in the US, methods included sending e-mail invitations to alumni from business schools at three universities and to a randomly selected sample of government managers selected from websites, as well as using a snowball sampling approach involving e-mail distribution lists and colleagues. After deletion of cases with missing values, the total useable sample for this study was comprised of 1553 managers from the US $(n=161)$, Canada $(n=194)$, Australia $(n=491)$, Finland $(n=255)$, and New Zealand $(n=452)$. Demographic information on each country sample is provided in Table 1. 
Table 1

Sample demographics

\begin{tabular}{lllcl}
\hline Sample & \% Female & Average age (years) & Average org. tenure (years) & \% Married or co-habitating \\
\hline Australia & 49.8 & 39.8 & 10.6 & 78.4 \\
Canada & 43.0 & 44.0 & 8.67 & 83.1 \\
Finland & 53.6 & 45.9 & 10.0 & 90.9 \\
New Zealand & 30.5 & 49.6 & 11.2 & 88.8 \\
US & 56.1 & 41.9 & 9.5 & 84.4 \\
\hline
\end{tabular}

\subsection{Measures}

A common questionnaire was used for all samples. For the Finnish sample, the original English questionnaire was translated and independently back-translated into English to check for inaccuracies.

\subsubsection{Work-family conflict}

Carlson et al.'s (2000) 18-item multidimensional measure of WFC was used. The scale assesses six dimensions as previously described, with 3 items per dimension. Response options ranged from 1 (Strongly disagree) to 5 (Strongly agree), with higher scores representing more conflict. Sample items include "I am often so emotionally drained when I get home from work that it prevents me from contributing to my family" for strainbased WIF, "The time I spend with my family often causes me not to spend time in activities at work that could be helpful to my career" for time-based FIW, and "The behaviors I perform that make me effective at work do not help me to be a better parent and spouse" for behavior-based WIF. Carlson et al. (2000) reported coefficient $\alpha$ s ranging from .78 to .87 across the six dimensions.

\subsubsection{Family-supportive organizational perceptions}

Allen's (2001) 14-item FSOP scale was used. Response options ranged from 1 (Strongly disagree) to 5 (Strongly agree), with higher scores indicating higher levels of organizational support. The items were preceded by the following instructions: "To what extent do you agree that each of the following statements represents the philosophy or beliefs of your organization (remember, these are not your own personal beliefs-but pertain to what you believe is the philosophy of your organization)." Sample items include "Work should be the primary priority in a person's life" (reverse-coded), "Expressing involvement and interest in nonwork matters is viewed as healthy," and "It is assumed that the most productive employees are those who put their work before their family" (reverse-coded). Allen (2001) reported a coefficient $\alpha$ of .91 for this scale.

\subsubsection{Employee satisfaction}

Job satisfaction was assessed with the 3-item Cammann, Fichman, Jenkins, and Klesh (1979) job satisfaction subscale from the Michigan Organizational Assessment Questionnaire. Response options ranged from 1 (Disagree very much) to 6 (Agree very much). A sample item is "All in all, I am satisfied with my job." Coefficient $\alpha$ s for this scale have ranged between .67 and .95 (Fields, 2002). Family satisfaction was measured with the 3-item scale used by Edwards and Rothbard (1999). We used the same six response options as those used for the job satisfaction measure. A sample item is "All in all, the family life I have is great." Edwards and Rothbard (1999) reported an $\alpha$ coefficient of .89 for this scale. Life satisfaction was assessed with Diener, Emmons, Larsen, and Griffin (1985) 5-item Satisfaction with Life Scale. Response options ranged from 1 (Strongly disagree) to 7 (Strongly agree). An example item is "In most ways, my life is close to my ideal." Diener et al. (1985) reported an $\alpha$ coefficient of .87 for this scale, and found that it correlates well with other measures of subjective well-being. For all three scales, higher scores represent higher levels of satisfaction.

\section{Results}

Tables 2-4 provide means, standard deviations, $\alpha$ coefficients of internal consistency, and zero-order correlations among all study variables. 
Table 2

Means, standard deviations, zero-order correlations, and $\alpha$ coefficients for all study variables (Australia and Canada)

\begin{tabular}{|c|c|c|c|c|c|c|c|c|c|c|c|c|c|c|}
\hline & Mean & $S D$ & 1 & 2 & 3 & 4 & 5 & 6 & 7 & 8 & 9 & 10 & Mean & $S D$ \\
\hline 1. WIF_t & 3.33 & 1.00 & .861 .84 & $.32^{* * *}$ & $.47^{* * *}$ & .13 & $.33^{* * *}$ & $.25^{* *}$ & $-.42^{* * *}$ & $-.24^{* *}$ & $-.38^{* * *}$ & $-.42^{* * *}$ & 2.95 & .96 \\
\hline 2. FIW_t & 2.31 & .82 & $.14^{* *}$ & .821 .81 & $.23^{* * *}$ & $.57^{* * *}$ & $.23^{* * *}$ & $.27^{* * * *}$ & -.11 & -.05 & $-.21^{* *}$ & $-.20^{* *}$ & 2.43 & .85 \\
\hline 3. WIF_s & 3.29 & 1.03 & $.59^{* * *}$ & $.25^{* * *}$ & .891 .86 & $.27^{* * *}$ & $.45^{* * *}$ & $.36^{* * *}$ & $-.34^{* * *}$ & $-.28^{* * *}$ & $-.34^{* * *}$ & $-.35^{* * *}$ & 2.90 & .94 \\
\hline 4. FIW_s & 2.06 & .81 & .07 & $.47^{* * *}$ & $.28^{* * *}$ & .891 .85 & $.20^{* *}$ & $.25^{* *}$ & -.09 & $-.19^{*}$ & $-.34^{* * *}$ & $-.23^{* *}$ & 2.09 & .74 \\
\hline 5. WIF_b & 2.68 & .84 & $.22^{* * *}$ & $.24^{* * *}$ & $.38^{* * *}$ & $.34^{* * * *}$ & .771 .84 & $.78^{* * * *}$ & $-.23^{* *}$ & -.08 & $-.20^{* *}$ & -.13 & 2.67 & .89 \\
\hline 6. FIW_b & 2.62 & .82 & $.19^{* * *}$ & $.22^{* * *}$ & $.33^{* * *}$ & $.33^{* * *}$ & $.70^{* * *}$ & .841 .88 & $-.23^{* *}$ & -.07 & $-.18^{*}$ & -.10 & 2.53 & .83 \\
\hline 7. FSOP & 2.72 & .78 & $-.43^{* * *}$ & -.04 & $-.44^{* * *}$ & -.03 & $-.24^{* * *}$ & $-.33^{* * *}$ & .921 .91 & $.47^{* * *}$ & $.21^{* *}$ & $.34^{* * *}$ & 2.60 & .73 \\
\hline 8. Jobsat & 4.75 & 1.20 & $-.26^{* * *}$ & -.07 & $-.35^{* * *}$ & $-.12^{*}$ & $-.17^{* * *}$ & $-.23^{* * *}$ & $.43^{* * *}$ & $.90 / .84$ & $.34^{* * *}$ & $.53^{* * *}$ & 4.86 & 1.14 \\
\hline 9. Famsat & 4.98 & 1.13 & $-.30^{* * *}$ & -.03 & $-.34^{* * *}$ & $-.27^{* * *}$ & $-.31^{* * *}$ & $-.26^{* * *}$ & $.32^{* * *}$ & $.32^{* * *}$ & $.92 / .95$ & $.63^{* * *}$ & 5.12 & 1.07 \\
\hline 10. Lifesat & 4.74 & 1.43 & $-.37^{* * *}$ & -.09 & $-.41^{* * *}$ & $-.25^{* * *}$ & $-.29^{* * *}$ & $-.33^{* * *}$ & $.41^{* * *}$ & $.46^{* * *}$ & $.67^{* * *}$ & $.90 / .89$ & 3.57 & .85 \\
\hline
\end{tabular}

Note. WIF, work interference with family; FIW, family interference with work; t, time-based; s, strain-based; b, behavior-based; FSOP, family-supportive organization perceptions; Jobsat, job satisfaction; Famsat, family satisfaction; Lifesat, life satisfaction. $\alpha$ coefficients italicized along main diagonal. Australia below main diagonal; Canada above main diagonal.

${ }^{*} p<.05$.

*** $p<.01$

$\begin{aligned} * * * & <.01 \\ p & <.001\end{aligned}$ 
Table 3

Means, standard deviations, zero-order correlations, and $\alpha$ coefficients for all study variables (New Zealand and US)

\begin{tabular}{|c|c|c|c|c|c|c|c|c|c|c|c|c|c|c|}
\hline & Mean & $S D$ & 1 & 2 & 3 & 4 & 5 & 6 & 7 & 8 & 9 & 10 & Mean & $S D$ \\
\hline 1. WIF_t & 3.18 & .97 & $.85 / .84$ & $.21^{* *}$ & $.63^{* * *}$ & .15 & .12 & .06 & $-.38^{* * *}$ & $-.36^{* * *}$ & -.05 & $-.25^{* *}$ & 3.18 & \\
\hline 2. FIW_t & 2.35 & .72 & $.24^{* * *}$ & $.75 / .83$ & $.25^{* *}$ & $.46^{* * *}$ & $.34^{* * *}$ & $.30^{* * *}$ & $-.28^{* *}$ & $-.24^{* *}$ & $-.30^{* * *}$ & $-.28^{* *}$ & 2.56 & \\
\hline 3. WIF_s & 2.94 & .93 & $.50^{* * *}$ & $.31^{* * *}$ & .851 .86 & $.25^{* *}$ & $.23^{* *}$ & .11 & $-.37^{* * *}$ & $-.39^{* * *}$ & -.13 & $-.34^{* * *}$ & 3.25 & 1.01 \\
\hline 4. FIW_s & 1.96 & .71 & $.20^{* * *}$ & $.44^{* * *}$ & $.29^{* * *}$ & .881 .90 & $.39^{* * *}$ & $.32^{* * *}$ & $-.17^{*}$ & $-.36^{* * *}$ & $-.45^{* * *}$ & $-.45^{* * *}$ & 2.15 & \\
\hline 5. WIF_b & 2.68 & .87 & $.21^{* * * *}$ & $.18^{* * *}$ & $.33^{* * *}$ & $.31^{* * * *}$ & .841 .87 & $.67^{* * *}$ & $-.29^{* * *}$ & $-.23^{* *}$ & $-.21^{*}$ & $-.26^{* *}$ & 2.61 & \\
\hline 6. FIW_b & 2.58 & .81 & $.14^{* *}$ & $.18^{* * *}$ & $.28^{* * *}$ & $.28^{* * *}$ & $.75^{* * *}$ & .871 .92 & -.15 & $-.20^{*}$ & $-.32^{* * *}$ & $-.26^{* *}$ & 2.57 & 2 \\
\hline 7. FSOP & 2.46 & .63 & $-.28^{* * *}$ & $-.18^{* * *}$ & $-.29^{* * *}$ & $-.22^{* * *}$ & $-.30^{* * *}$ & $-.23^{* * *}$ & .891 .89 & $.47^{* * *}$ & .11 & $37^{* * *}$ & 2.85 & \\
\hline 8. Jobsat & 5.06 & 1.06 & -.09 & $-.13^{* *}$ & $-.28^{* * *}$ & $-.12^{*}$ & $-.18^{* * *}$ & $-.14^{* *}$ & $.38^{* * * *}$ & .851 .89 & $.25^{* *}$ & $.53^{* * *}$ & 4.64 & 1.38 \\
\hline 9. Famsat & 5.15 & 1.05 & $-.25^{* * *}$ & $-.13^{* *}$ & $-.35^{* * *}$ & $-.33^{* * *}$ & $-.27^{* * *}$ & $-.23^{* * *}$ & $.23^{* * *}$ & $.36^{* * *}$ & .921 .96 & $.67^{* * *}$ & 4.74 & 1.27 \\
\hline 10. Lifesat & 4.99 & 1.34 & $-.30^{* * *}$ & $-.19^{* * *}$ & $-.40^{* * *}$ & $-.25^{* * *}$ & $-.27^{* * *}$ & $-.24^{* * *}$ & $.36^{* * *}$ & $.41^{* * *}$ & $.66^{* * *}$ & $.90 / .90$ & 3.28 & .95 \\
\hline
\end{tabular}

Note. WIF, work interference with family; FIW, family interference with work; t, time-based; s, strain-based; b, behavior-based; FSOP, family-supportive organization perceptions; Jobsat, job satisfaction; Famsat, family satisfaction; Lifesat, life satisfaction. $\alpha$ coefficients italicized along main diagonal. New Zealand below main diagonal; US above main diagonal. ${ }^{*} p<.05$. ${ }_{* * *}^{* *} p<.01$.

*** $p<.001$. 
Table 4

Means, standard deviations, zero-order correlations, and $\alpha$ coefficients for all study variables (Finland)

\begin{tabular}{|c|c|c|c|c|c|c|c|c|c|c|c|c|}
\hline & Mean & $S D$ & 1 & 2 & 3 & 4 & 5 & 6 & 7 & 8 & 9 & 10 \\
\hline 1. WIF_t & 2.97 & .96 & .84 & & & & & & & & & \\
\hline 2. FIW_t & 2.25 & .85 & $.37^{* * *}$ & .82 & & & & & & & & \\
\hline 3. WIF_s & 2.95 & .86 & $.50^{* * *}$ & $.35^{* * *}$ & .80 & & & & & & & \\
\hline 4. FIW_s & 1.83 & .72 & $.13^{*}$ & $.50^{* * *}$ & $.16^{*}$ & .86 & & & & & & \\
\hline 5. WIF_b & 2.96 & .79 & $.28^{* * *}$ & $.26^{* * *}$ & $.28^{* * *}$ & $.28^{* * *}$ & .75 & & & & & \\
\hline 6. FIW_b & 2.75 & .78 & $.19^{* *}$ & $.30^{* * *}$ & $.21^{* *}$ & $.26^{* * *}$ & $.59^{* * *}$ & .86 & & & & \\
\hline 7. FSOP & 2.68 & .65 & $-.43^{* * *}$ & $-.29^{* * *}$ & $-.47^{* * *}$ & $-.22^{* * *}$ & $-.35^{* * *}$ & $-.36^{* * *}$ & .91 & & & \\
\hline 8. Jobsat & 4.77 & 1.04 & $-.20^{* *}$ & $-.24^{* * *}$ & $-.23^{* * *}$ & $-.17^{* *}$ & $-.22^{* * *}$ & $-.26^{* * *}$ & $.45^{* * *}$ & .86 & & \\
\hline 9. Famsat & 4.90 & 1.09 & $-.14^{*}$ & $-.19^{* *}$ & $-.22^{* *}$ & $-.37^{* * *}$ & $-.31^{* * *}$ & $-.18^{* *}$ & $.20^{* *}$ & $.19^{* *}$ & .96 & \\
\hline 10. Lifesat & 5.11 & 1.10 & $-.27^{* * *}$ & $-.23^{* * *}$ & $-.30^{* * *}$ & $-.34^{* * *}$ & $-.31^{* * *}$ & $-.25^{* * *}$ & $.37^{* * *}$ & $.46^{* * *}$ & $.57^{* * *}$ & .88 \\
\hline
\end{tabular}

Note. WIF, work interference with family; FIW, family interference with work; t, time-based; s, strain-based; b, behavior-based; FSOP, family-supportive organization perceptions; Jobsat, job satisfaction; Famsat, family satisfaction; Lifesat, life satisfaction. $\alpha$ coefficients italicized along main diagonal.

${ }^{*} p<.05$.

${ }_{* * *}^{* *} p<.01$.

$p<.001$.

We based our analytic procedure for testing our model on Vandenberg and Lance's (2000) structural equation modeling method for testing scale invariance across different samples. We followed four steps: (1) an omnibus test of measurement invariance; (2) a test of configural (factor structure) invariance; (3) a test of metric (factor loading) invariance; and (4) a test of theoretical structural model invariance.

In terms of model fit indices, besides reporting the chi-square statistic (which tends to be inflated in large samples; Kline, 2003), associated degrees of freedom, and the chi-square to degrees of freedom ratio (Byrne, 1989), we followed Vandenberg and Lance's (2000) recommendations by reporting the Tucker-Lewis index (TLI) (Tucker \& Lewis, 1973), now often referred to as the nonnormed fit index (NNFI); the relative noncentrality index (RNI) (McDonald \& Marsh, 1990); and the root mean error of approximation (RMSEA) (Steiger, 1990). We also included the $p$ value indicating the probability that the population RMSEA was no greater than 0.05 .

The omnibus test involved testing whether the variance-covariance matrix including the items for FSOP, all six WFC dimensions, job satisfaction, family satisfaction, and life satisfaction (43 items in total) was invariant across our five samples. Good fit would suggest that the covariances among these items, resulting from common factors they reflect and from relationships among these factors, were similar across samples.

Results for the omnibus test suggest that the variance-covariance matrix including items from all scales was invariant across all five samples. More specifically, the chi-square $(5905.47 ; p<.001)$ to degrees of freedom (3784) ratio (1.56) was below the upper threshold of 2.00 recommended by Byrne (1989), the TLI (.93) and RNI (.95) were both above the minimally acceptable value of .90 (Kline, 2003; Vandenberg \& Lance, $2000)$, and the RMSEA (.02; $p=1.00)$ was below 0.08 , suggesting a reasonable error or approximation in the population (Jöreskog \& Sörbom, 1996).

Our second step involved determining whether a given factor structure would yield good fit to the data across all samples. Replicating the approach used by Carlson et al. (2000), we tested four measurement models. Model 1 involved a total of five factors, one for FSOP, one for "overall WFC," which collapsed across all six WFC dimensions, and one for each type of satisfaction (job, family, and life). Model 2 involved a total of 6 factors. It differed from Model 1 only in that the "overall WFC" factor was replaced with two factors, each representing a direction of WFC (WIF and FIW) but collapsing across the three forms (time-, strain-, and behavior-based). Model 3 involved a total of 7 factors. It differed from the previous model by including three WFC factors, each representing a form of WFC, but collapsing across both WFC directions. Finally, Model 4 included a total of 10 factors, involving all six WFC dimensions.

Results presented in Table 5 indicate that Model 4 was the only model to yield satisfactory fit. Moreover, the chi-square differences between Model 4 and all other models were statistically significant at a level of .001. 
Table 5

Tests of configural invariance

\begin{tabular}{llllllll}
\hline Model & $\chi^{2}$ & $d f$ & $\chi^{2} / d f$ & TLI & RNI & RMSEA & $p$ \\
\hline 1 & $15,232.31$ & 4250 & 3.58 & .70 & .72 & .04 & .04 \\
2 & $13,353.94$ & 4225 & 3.16 & .75 & .77 & .04 \\
3 & $10,319.45$ & 3356 & 3.08 & .81 & .83 & .04 & 1.00 \\
4 & $5,828.10$ & 3260 & 1.79 & .93 & .94 & .02 & 1.00 \\
\hline
\end{tabular}

Note. All $\chi^{2}$ values are statistically significant at a level of .001 .

This confirmed that Carlson et al.'s (2000) proposed six-factor solution explained covariation among the 18 WFC items better than did alternative factor structures across all samples.

Our third step involved testing whether the factor loadings of like items were equivalent across samples (metric invariance). We found evidence of metric invariance, with a chi-square $(7110.88 ; p<.001)$ to degrees of freedom (4207) ratio of 1.69, TLI and RNI values of .92, and an RMSEA value of .02 ( $p=1.00)$. These findings suggest that like items appear to have reflected their corresponding factors similarly across samples.

Our fourth step involved testing whether the paths linking the latent variables in our model not only reasonably explained observed relationships among these variables, but whether the path coefficients were similar across samples. We considered that WFC dimensions may covary for reasons other than having FSOP as a common cause. Other unmeasured common causes may exist (e.g., Spector et al., 2007). WFC dimensions may also covary because they all denote WFC. We therefore allowed the disturbance terms of the six WFC factors to covary. For similar reasons, we also allowed the disturbance terms of the job and family satisfaction factors to covary.

Our proposed theoretical structural model yielded good fit to the data, with a chi-square $(7615.36 ; p<.001)$ to degrees of freedom (4334) ratio of 1.75 , a TLI value of .91, an RNI value of .92, and an RMSEA value of $.02(p=1.00)$. Fig. 2 presents the standardized path coefficients linking the variables in our model.

As expected, the modeling results showed that FSOP related negatively to each of the six WFC dimensions. However, FSOP appeared to relate more strongly to time-based WIF than to time-based FIW, and more strongly to strain-based WIF than to strain-based FIW. Because this pattern is consistent with previous research suggesting elements of the work domain are more likely to influence WIF than FIW, we tested

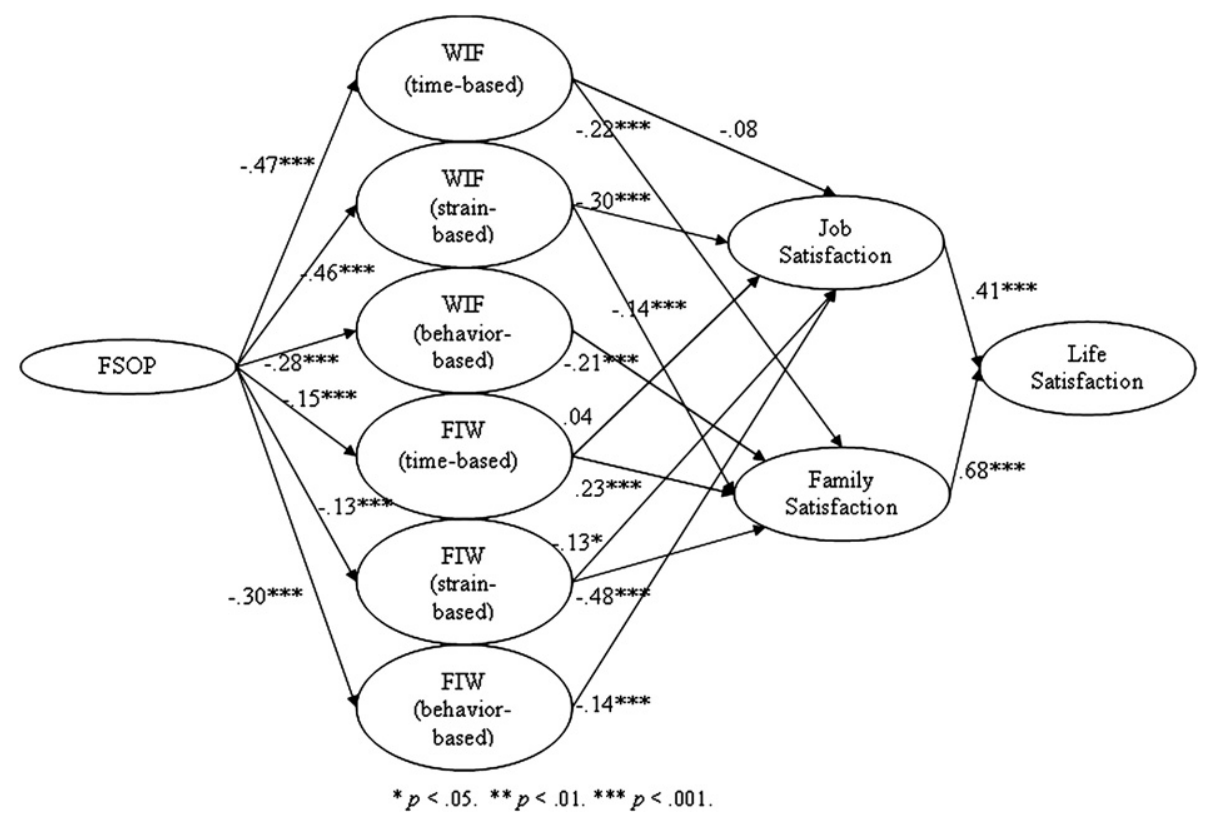

Fig. 2. Standardized path coefficients of theoretical model. 
whether these differences were statistically significant. To this end, we retested our structural model twice: once with the paths linking FSOP to time-based FIW and to time-based WIF set as equal, and once with the paths linking FSOP to strain-based FIW and to strain-based WIF set as equal. In both cases, setting the paths as equal yielded a significantly larger chi-square $\left(\Delta \chi^{2}=81.04, d f=1, p<.001\right.$, and $\Delta \chi^{2}=95.64, d f=1$, $p<.001$, respectively), indicating that the path differences observed were statistically significant.

Modeled relationships of time- and strain-based WIF with job and family satisfaction were not completely as expected. Both forms of WIF related negatively as predicted to family satisfaction. However, while strainbased WIF related negatively to job satisfaction, time-based WIF was not significantly related to this attitude. Relationships between time- and strain-based FIW and job and family satisfaction were also mixed. While strain-based FIW related negatively as expected to job and to family satisfaction, time-based FIW was not significantly related to job satisfaction and related positively to family satisfaction. As anticipated, behavior-based WIF related negatively to family satisfaction, and behavior-based FIW related negatively to job satisfaction.

Potentially contradicting previous research suggesting that WIF affects the family domain more than the work domain and that FIW affects the work domain more than the family domain (Frone, 2003), our modeling results showed that strain-based WIF appeared to relate more strongly to job satisfaction than to family satisfaction, and strain-based FIW seemed to relate more strongly to family satisfaction than to job satisfaction. Using the same approach described above, we found that these two differences were statistically significant $\left(\Delta \chi^{2}=7.24, d f=1, p<.01\right.$, and $\Delta \chi^{2}=28.14, d f=1, p<.001$, respectively).

The significant positive paths linking job and family satisfaction to life satisfaction, combined with our model's satisfactory fit index values, are consistent with the position that WFC dimensions indirectly relate to life satisfaction through job and family satisfaction. However, not all indirect relationships conceptualized in our model were supported. The indirect relationship between time-based WIF and life satisfaction through job satisfaction was not supported because time-based WIF was not significantly related to job satisfaction in the model. Similarly, the indirect relationships between time-based FIW and life satisfaction through job and family satisfaction were not supported because time-based FIW did not relate as expected to job and family satisfaction.

\section{Discussion}

Our theoretical structural model was invariant across samples from five different individualistic countries. This supports the view that relationships among the constructs we measured would be generalizable across samples drawn from nations that are similarly individualistic. This also lessens the concern that our findings reflect substantial sampling error.

The pattern of differential relationships we observed linking the six WFC dimensions to other variables in our model generally supports Greenhaus and Beutell's (1985) arguments for differentiating between forms and directions of WFC. Collapsing across forms and/or directions of WFC may potentially blur our understanding of the WFC phenomenon. For example, although we found that FSOP related negatively to each of the six WFC dimensions, thereby supporting our proposition that the work domain may help avert both directions of WFC, we found that FSOP related more strongly to time- and strain-based WIF than to time- and strainbased FIW. These results are generally consistent with past research suggesting that the work domain is a more proximal antecedent of WIF than of FIW (e.g., Frone et al., 1997). We had initially argued that a family-supportive work environment could help reduce time- and strain-based FIW by lessening work-related pressures when family demands are great. However, our findings suggest that a family-supportive work environment may not substantially alleviate the negative impact of excessive family demands on work activities. Despite a reduction in work-related pressure afforded by a family-supportive work environment, family demands may still be important enough to cause time- and strain-based FIW. Thus, such a work environment would appear less helpful at reducing time- and strain-based FIW than time- and strain-based WIF. This would be consistent with meta-analytic research showing that work schedule flexiblity is more strongly related to WIF than to FIW (Byron, 2005).

Finding that both directions of behavior-based WFC related as predicted to FSOP is consistent with the notion that behavioral norms in a family-supportive work environment and in most families are similar, 
thereby limiting the likelihood that such conflict will arise. Also, that both directions of behavior-based WFC related as expected job and family satisfaction supports the idea that incompatible behavioral role expectations may cause problems that reduce role satisfaction. These results are particularly important in light of the fact that little research has examined the potential antecedents and outcomes of behavior-based conflict (Bruck, Allen, \& Spector, 2002; Carlson et al., 2000).

In terms of relationships between time- and strain-based WFC dimensions and role-specific satisfaction, we had originally argued that employees would feel less satisfied with their family and their job as a result of insufficient resources being available to meet role expectations. Employees may become less satisfied in a role because they have insufficient resources to be successful in that role, and because they blame (and thus become less satisfied with) one role for depleting resources they would like to use in the other role. Our findings suggest that these arguments are more strongly supported in the case of strain-based than time-based WFC. Employees may find role strain spilling over into another role more troubling than time-based role incompatibilities. Moreover, having found that strain-based WIF relates more strongly to job than to family dissatisfaction, and that strain-based FIW relates more strongly to family than to job dissatisfaction, it may be overly simplistic to assume that job dissatisfaction would only result from FIW (and not WIF) and that family dissatisfaction would only stem from WIF (and not FIW).

The unexpected positive relationship between time-based FIW and family satisfaction is interesting. Perhaps this relationship exists because the more people are happy at home, the more they wish to spend time there, resulting in less time being available for work. This would mean that family satisfaction would influence time-based FIW, not the reverse. Because the zero-order correlation between time-based FIW and family satisfaction was negative in each sample, our finding may reflect a suppressor effect, whereby the unique positive relationship between these two variables may only have emerged once variance shared with other WFC dimensions was partialed out. Thus, interpretation of the relationship between time-based FIW and family satisfaction should be viewed cautiously.

Finally, having found that job and family satisfaction explain why some WFC dimensions relate negatively to life satisfaction, we have reason to believe that a family-supportive work environment can potentially strengthen life satisfaction by reducing work-family incompatibilities that lessen their satisfaction at work and at home. This implies that employees' perceptions of their work environment's family-supportiveness may play a significant role in their overall level of enjoyment in life.

\subsection{Practical implications}

We would encourage organizations to ensure a family-supportive work environment for their employees in order to help them better juggle work and family demands in ways that can benefit employees and organizations. Based on Allen's (2001) findings, methods of ensuring such a work environment could include providing guidance to supervisors on how to be supportive and tolerant of their employees' family commitments, and making formal family-friendly benefits available, such as those that provide them with more scheduling flexibility (e.g., compressed work weeks, part-time work, flextime). Research by Shinn, Wong, Simko, and Ortiz-Torres (1989) suggests promising actions supervisors can take to show support for employees' family obligations, such as switching schedules (regular hours, overtime hours, and vacation) among staff members to accommodate an employee's family responsibilities, showing sympathy for employees' needs as working parents, taking the time to listen to employees' family-related problems, and sharing advice with employees on how to more effectively balance work and family responsibilities. It would also be potentially fruitful for supervisors to expect or encourage all employees in their group to show support for each other's family obligations given research suggesting that social support from co-workers may help reduce the strain experienced by employees (Beehr, Farmer, Glazer, Gudanowski, \& Nair, 2003; Beehr, Jex, Stacy, \& Murray, 2000).

\section{Conclusion}

This study contributes to the existing body of knowledge on WFC in two ways. First, data from five independent samples are consistent with a theoretical model where working in a family-supportive environment reduces multiple WFC dimensions, which enhances job and family satisfaction, consequently increasing life 
satisfaction. Second, our results further support the distinction between the six dimensions of WFC theorized by Greenhaus and Beutell (1985) and operationalized by Carlson et al. (2000).

\section{Acknowledgment}

This research was supported in part by Grant 410-2006-0209 from the Social Sciences and Humanities Research Council of Canada.

\section{References}

Allen, T. D. (2001). Family-supportive work environments: The role of organization perceptions. Journal of Vocational Behavior, 58, 414-435.

Allen, T. D., Herst, D. E. L., Bruck, C. S., \& Sutton, M. (2000). Consequences associated with work-to-family conflict: A review and agenda for future research. Journal of Occupational Health Psychology, 5, 278-308.

Aryee, S., Fields, D., \& Luk, V. (1999). A cross-cultural test of a model of the work-family interface. Journal of Management, 25, 491-511.

Beehr, T. A., Farmer, S. J., Glazer, S., Gudanowski, D. M., \& Nair, V. N. (2003). The enigma of social support and occupational stress: Source congruence and gender role effects. Journal of Occupational Health Psychology, 8, 220-231.

Beehr, T. A., \& Glazer, S. (2005). Organizational role stress. In J. Barling, E. K. Kelloway, \& M. R. Frone (Eds.), Handbook of work stress (pp. 7-33). Thousand Oaks, CA: Sage.

Beehr, T. A., Jex, S. M., Stacy, B. A., \& Murray, M. A. (2000). Work stressors and coworker support as predictors of individual strain and job performance. Journal of Organizational Behavior, 21, 391-405.

Bliese, P. D., \& Britt, T. W. (2001). Social support, group consensus and stressor-strain relationships: Social context matters. Journal of Organizational Behavior, 22, 425-436.

Bruck, C. S., Allen, T. D., \& Spector, P. E. (2002). The relation between work-family conflict and job satisfaction: A finer-grained analysis. Journal of Vocational Behavior, 60, 336-353.

Byrne, B. M. (1989). A primer of LISREL: Basic applications and programming for confirmatory factor analytic models. New York: Springer.

Byron, K. (2005). A meta-analytic review of work-family conflict and its antecedents. Journal of Vocational Behavior, 67, 169-198.

Cammann, C., Fichman, M., Jenkins, D., \& Klesh, J. (1979). The Michigan Organizational Assessment Questionnaire. Unpublished manuscript. Ann Arbor: University of Michigan.

Carlson, D. S., \& Kacmar, K. M. (2000). Work-family conflict in the organization: Do life role values make a difference?. Journal of Management 26, 1031-1054.

Carlson, D. S., Kacmar, K. M., \& Williams, L. J. (2000). Construction and initial validation of a multidimensional measure of workfamily conflict. Journal of Vocational Behavior, 56, 249-276.

Diener, E., Emmons, R. A., Larsen, R. J., \& Griffin, S. (1985). The satisfaction with life scale. Journal of Personality Assessment, 49, 71-75.

Eby, L. T., Casper, W. J., Lockwood, A., Bordeaux, C., \& Brinley, A. (2005). Work and family research in IO/OB: Content analysis and review of the literature (1980-2002). Journal of Vocational Behavior, 66, 124-197.

Edwards, J. R., \& Rothbard, N. P. (1999). Work and family stress and well-being: An examination of person-environment fit in the work and family domains. Organizational Behavior and Human Decision Processes, 77, 85-129.

Edwards, J. R., \& Rothbard, N. P. (2000). Mechanisms linking work and family: Clarifying the relationship between work and family constructs. Academy of Management Review, 25, 178-199.

Fields, D. L. (2002). Taking the measure of work: A guide to validated scales for organizational research and diagnosis. Thousand Oaks: Sage.

Friedman, D. E. (1990). Work and family: The new strategic plan. Human Resource Planning, 13, 79-89.

Friedman, D. E., \& Galinsky, E. (1992). Work and family issues: A legitimate business concern. In S. Zedeck (Ed.), Work, families, and organizations (pp. 168-207). San Francisco, CA: Jossey-Bass Publishers.

Frone, M. R. (2003). Work-family balance. In J. C. Quick \& L. E. Tetrick (Eds.), Handbook of occupational health psychology (pp. 143-162). Washington, DC: American Psychological Association.

Frone, M. R., Russell, M., \& Cooper, M. L. (1992). Antecedents and outcomes of work-family conflict: Testing a model of the workfamily interface. Journal of Applied Psychology, 77, 65-78.

Frone, M. R., Yardley, M., \& Markel, K. S. (1997). Developing and testing a model of the work-family interface. Journal of Vocational Behavior, 50, 146-167.

Greenhaus, J. H., \& Beutell, N. J. (1985). Sources of conflict between work and family roles. Academy of Management Review, 10, 76-88.

Greenhaus, J. H., Parasuraman, S., \& Collins, K. M. (2001). Career involvement and family involvement as moderators of relationships between work-family conflict and withdrawal from a profession. Journal of Occupational Health Psychology, 6, 91-100.

Hofstede, G. (1980). Culture's consequences. Beverly Hills: Sage.

House, R. J., Hanges, P. J., Javidan, M., Dorfman, P. W., \& Gupta, V. (2004). Culture, leadership, and organizations: The GLOBE study of 62 societies. Thousand Oaks: Sage.

James, L. R., \& McIntyre, M. D. (1996). Perceptions of organizational climate. In K. R. Murphy (Ed.), Individual differences and behavior in organizations (pp. 416-450). San Francisco: Jossey-Bass. 
Jöreskog, K., \& Sörbom, D. (1996). LISREL 8 user's guide. Chicago: Scientific Software.

Kahn, R. L., Wolfe, D. M., Quinn, R. P., Snoek, J. D., \& Rosenthal, R. A. (1964). Organizational stress: Studies in role conflict and ambiguity. New York: Wiley.

Katz, D., \& Kahn, R. L. (1978). The social psychology of organizations (2nd ed.). New York: John Wiley.

Kirchmeyer, C., \& Cohen, A. (1999). Different strategies for managing the work-non-work interface: A test for unique pathways to outcomes. Work and Stress, 13, 59-73.

Kline, R. B. (2003). Principles and practice of structural equation modeling. New York: The Guilford Press.

Lapierre, L. M., Hackett, R. D., \& Taggar, S. (2006). A test of the links between family interference with work, job enrichment and leadermember exchange. Applied Psychology: An International Review, 55, 489-511.

Liu, C., Borg, I., \& Spector, P. E. (2004). Measurement equivalence of the German Job Satisfaction Survey used in a multinational organization: Implications of Schwartz's culture model. Journal of Applied Psychology, 89, 1070-1082.

McDonald, R. P., \& Marsh, H. W. (1990). Choosing a multivariate model: Noncentrality and goodness-of-fit. Psychological Bulletin, 107, 247-255.

Moons, P., Budts, W., \& De Geest, S. (2006). Critique on the conceptualization of quality of life: A review and evaluation of different conceptual approaches. International Journal of Nursing Studies, 43, 891-901.

O'Driscoll, M. P., Ilgen, D. R., \& Hildreth, K. (1992). Time devoted to job and off-job activities, interrole conflict, and affective experiences. Journal of Applied Psychology, 77, 272-279.

Ostroff, C., Kinicki, A. J., \& Tamkins, M. M. (2003). Organizational culture and climate. In W. C. Borman, D. R. Ilgen, \& R. J. Klimoski (Eds.), Handbook of psychology. Industrial and organizational psychology (Vol. 12, pp. 565-594). Hoboken, NJ: John Wiley \& Sons, Inc.

Perlow, L. A. (1995). Putting the work back into work/family. Group \& Organization Management, 20, $227-239$.

Rice, R. W., Frone, M. R., \& McFarlin, D. B. (1992). Work-nonwork conflict and the perceived quality of life. Journal of Organizational Behavior, 13, 155-168.

Schwartz, S. H. (1994). Beyond individualism and collectivism: New cultural dimensions of values. In U. Kim, H. C. Triandis, C. Kagitçibasi, S.-C. Choi, \& G. Yoon (Eds.), Individualism and collectivism: Theory, method, and applications (pp. 85-122). Newbury Park, CA: Sage.

Shinn, M., Wong, N. W., Simko, P. A., \& Ortiz-Torres, B. (1989). Promoting the well-being of working parents: Coping, social support, and flexible job schedules. American Journal of Community Psychology, 17, 31-55.

Spector, P. E., Allen, T. A., Poelmans, S. A. Y., Lapierre, L. M., Cooper, C. L., O’Driscoll, M., et al. (2007). Cross-national differences in relationships of work demands, job satisfaction and turnover intentions with work-family conflict. Personnel Psychology, 60, 805-835.

Spector, P. E., Cooper, C. L., Poelmans, S., Allen, T. D., O’Driscoll, M., Sanchez, J. I., et al. (2004). A cross-national comparative study of work/family stressors, working hours, and well-being: China and Latin America vs the Anglo world. Personnel Psychology, 57, 119-142.

Steiger, J. H. (1990). Structural model evaluation and modification: An interval estimation approach. Multivariate Behavioral Research, $25,173-180$.

Thompson, C. A., Beauvais, L. L., \& Lyness, K. S. (1999). When work-family benefits are not enough: The influence of work-family culture on benefit utilization, organizational attachment, and work-family conflict. Journal of Vocational Behavior, 54, $392-415$.

Tucker, L. R., \& Lewis, C. (1973). The reliability coefficient for maximum likelihood factor analysis. Psychometrika, $38,1-10$.

Vandenberg, R. J., \& Lance, C. E. (2000). A review and synthesis of the measurement invariance literature: Suggestions, practices, and recommendations for organizational research. Organizational Research Methods, 3, 4-70. 